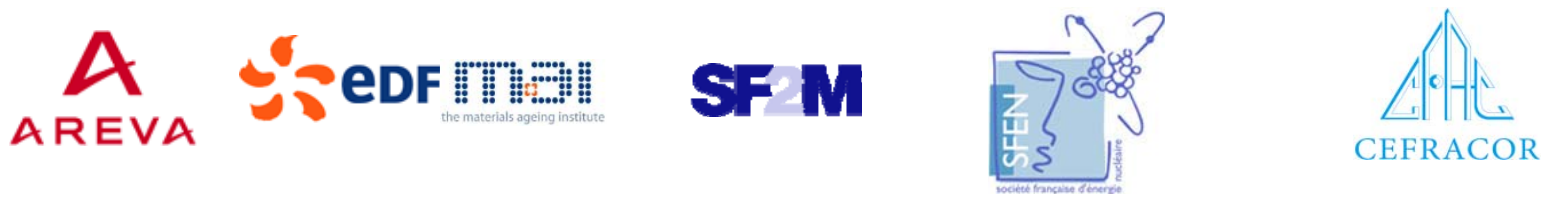

\section{MIN口S}

Centre of Excellence for Nuclear Materials

\section{Workshop}

Materials Innovation for Nuclear Optimized Systems

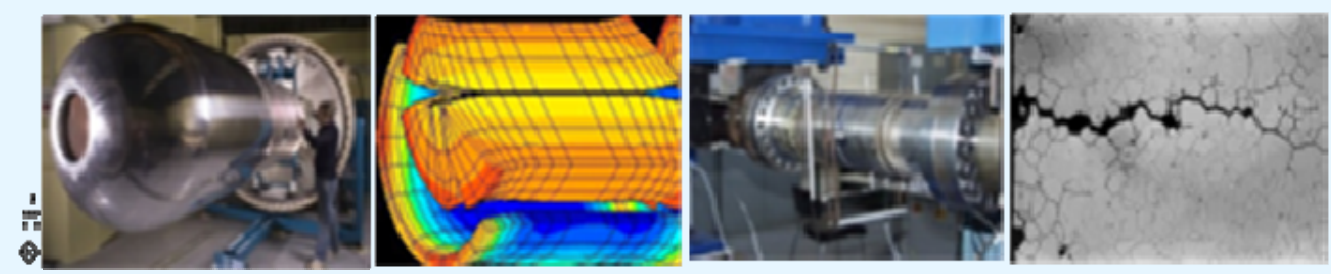

December 5-7, 2012, CEA - INSTN Saclay, France

\section{Pierre JOLY et al. \\ AREVA NP (France)}

Thermal Ageing Effects: Examples on Materials of PWR and Preventive Measures in the Design of EPR ${ }^{\mathrm{TM}}$ Plants

Workshop organized by:

Christophe GALLÉ, CEA/MINOS, Saclay - christophe.galle@cea.fr Constantin MEIS, CEA/INSTN, Saclay - constantin.meis@cea.fr 
MINDS

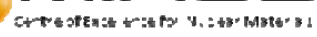

\title{
Thermal Ageing Effects: Examples on Materials of PWR and Preventive Measures in the Design of EPR ${ }^{\mathrm{TM}}$ Plants
}

\author{
Pierre JOLY ${ }^{1}$, Pascal OULD ${ }^{1}$, François ROCH ${ }^{1}$ \\ ${ }^{1}$ AREVA NP - Engineering E\&P, Division of Primary Components - Materials Department (Paris, la Défense, France)
}

Even though the operating temperature of Pressurized Water Reactors (PWR) is moderate (around $300^{\circ} \mathrm{C}$ ), experience gained on some of the materials used for the manufacturing of components of existing PWRs, shows that they may be sensitive to thermal ageing phenomena. This type of ageing mechanism essentially causes an embrittlement, i.e. a reduction of fracture toughness, or an increase of the ductile to brittle transition temperature (for bainitic or martensitic steels), as the time in service increases. In the presentation, three examples of thermal ageing phenomena affecting PWR components are treated.

The first one deals with the cast duplex austenitic-ferritic stainless steels, which are used in various locations of the main coolant piping such as elbows, nozzles, centrifugally cast straight sections, etc... (Fig. 1). The second example is about martensitic stainless steels, mainly used for bolting and internal components of valves (Fig. 2). Eventually, the third example is the case of bainitic low alloy steel, used to manufacture the large primary pressure vessels such as the Reactor Pressure Vessel, the Steam Generator, and the Pressurizer (Fig. 1). In all these examples, the presentation illustrates how these degradation mechanisms are known, through laboratory studies. These studies allow in particular deriving the main parameters of the material itself and of the service conditions which govern the embrittlement, and allow to derive predictive models of embrittlement, accurate enough for engineering applications (Fig. 3). In some cases this laboratory knowledge is complemented and validated by field experience, obtained through the surveillance of components in service, or through expertise programs conducted on decommissioned components.

Finally, from the knowledge on these phenomena, accumulated in the research programs, examples of precautions taken in order to eradicate or to mitigate the known effects of thermal ageing in the design of new EPR ${ }^{\mathrm{TM}}$ plants are presented.

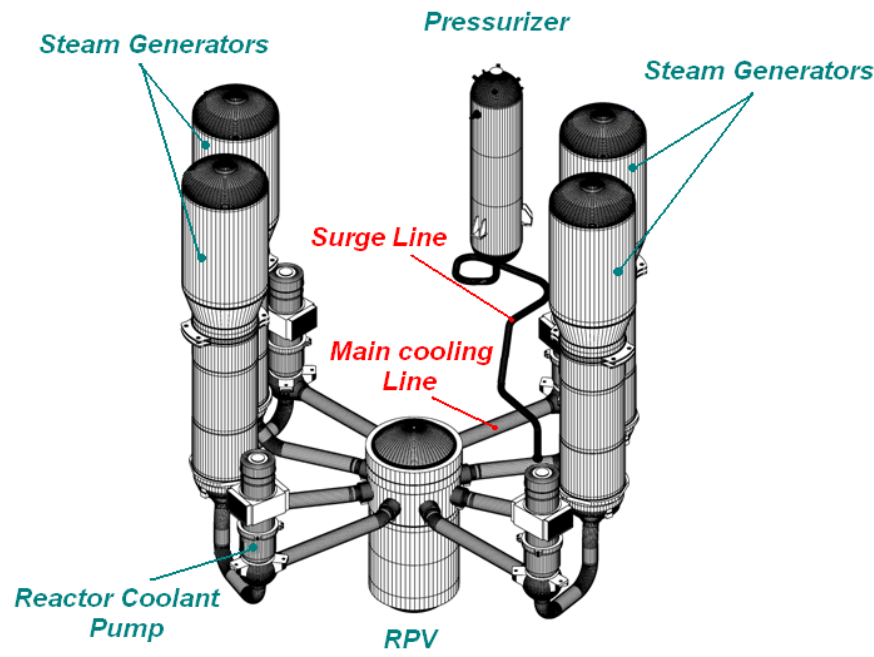

Fig. 1: Layout of the main components of the primary circuit of a 4 loop Pressurized Water Reactor. 


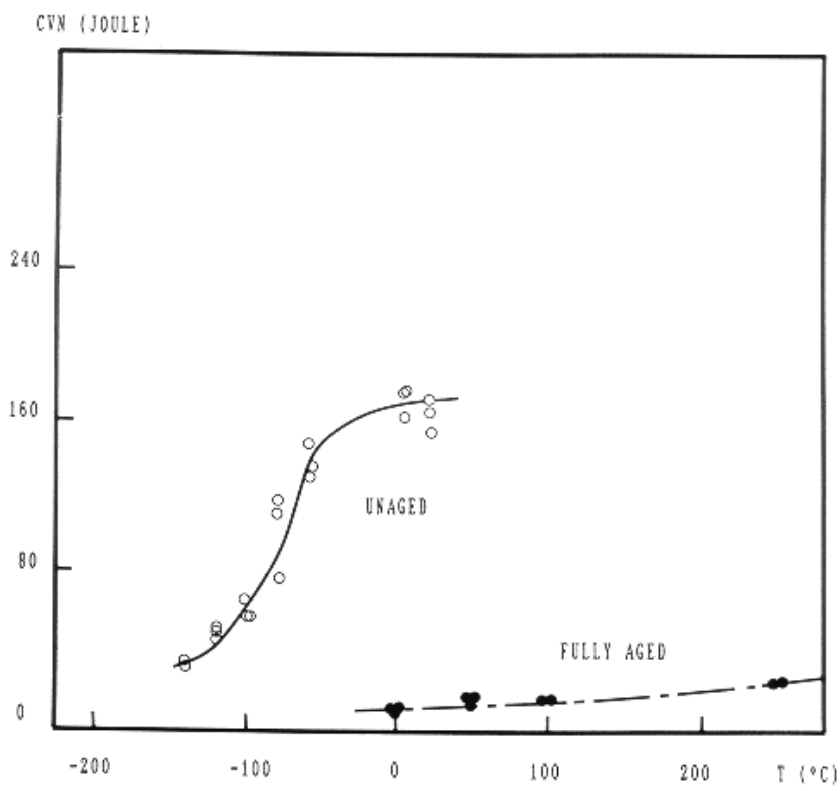

Fig. 2: Example of the effect of thermal ageing on the Charpy V Impact Energy transition curve of a typical 17-4 PH martensitic stainless steel used for valve stems applications.

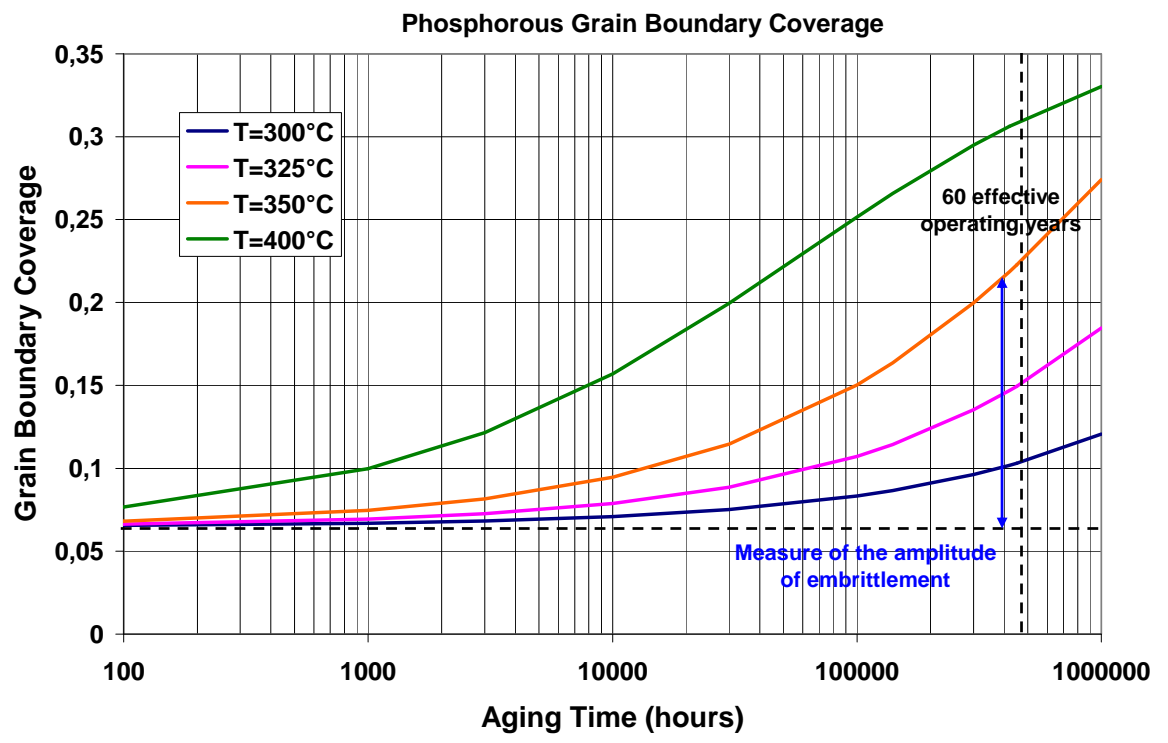

Fig. 3: Example of modelling of the kinetics of embrittlement of low alloy Pressure Vessel steel, at different temperatures by grain boundary segregation of Phosphorous. 